\title{
Bradycardia: changes in intrinsic rate rather than cardiac autonomic modulation
}

\author{
Anthony S. Leicht
}

Received: 19 May 2013/Accepted: 25 June 2013/Published online: 25 July 2013

(C) Springer-Verlag Berlin Heidelberg 2013

The recent cross-sectional comparison by Molina et al. [1] highlights again the growing evidence for a reduced, cardiac intrinsic rate responsible for exercise-induced bradycardia (EIB). Several longitudinal studies [2-4] have previously shown EIB without alterations in cardiac autonomic modulation as evidenced by heart rate variability (HRV). While HRV changes have been reported to be dependent on exercise training intensity [5] and initial high HRV levels in young healthy adults [2,6], these past and current results point to localised changes within the myocardium as the primary contributor to EIB. Chronic, mechanical stretching of the sino-atrial node [2-4], changes in ionic concentration within the sino-atrial node [7], and localised changes in myocardial conduction [8] appear to play a role in the development of EIB. The current work of Molina [1] adds to that of others previously and further highlights the necessity to examine sino-atrial function as a key mechanism for EIB.

Conflict of interest The corresponding author states that there is no conflict of interest.

\section{References}

1. Molina GE, Porto LG, Fontana KE, Junqueira LF Jr (2013) Unaltered R-R interval variability and bradycardia in cyclists as compared with non-athletes. Clin Auton Res. doi:10.1007/s10286013-0196-8

2. Leicht AS, Allen GD, Hoey AJ (2003) Influence of age and moderate-intensity exercise training on heart rate variability in young and mature adults. Can J Appl Physiol 28(3):446-461

3. Bonaduce D, Petretta M, Cavallaro V, Apicella C, Ianniciello A, Romano M, Breglio R, Marciano F (1998) Intensive training and cardiac autonomic control in high level athletes. Med Sci Sports Exerc 30(5):691-696

4. Katona PG, McLean M, Dighton DH, Guz A (1982) Sympathetic and parasympathetic cardiac control in athletes and nonathletes at rest. J Appl Physiol 52(6):1652-1657

5. Leicht AS, Allen GD, Hoey AJ (2003) Influence of intensive cycling training on heart rate variability during rest and exercise. Can J Appl Physiol 28(6):898-909

6. Kiviniemi AM, Hautala AJ, Seppanen T, Makikallio TH, Huikuri HV, Tulppo MP (2004) Saturation of high-frequency oscillations of R-R intervals in healthy subjects and patients after acute myocardial infarction during ambulatory conditions. Am J Physiol Heart Circ Physiol 287(5):H1921-H1927

7. Raab W (1969) Myocardial electrolyte derangement: crucial feature of pluricausal, so-called coronary, heart disease (dysionic cardiopathy). Ann N Y Acad Sci 147(17):627-686

8. Such L, Rodriguez A, Alberola A, Lopez L, Ruiz R, Artal L, Pons I, Pons ML, Garcia C, Chorro FJ (2002) Intrinsic changes on automatism, conduction, and refractoriness by exercise in isolated rabbit heart. J Appl Physiol 92(1):225-229

\footnotetext{
A. S. Leicht $(\bowtie)$

Institute of Sport and Exercise Science, James Cook University,

Townsville, QLD 4811, Australia

e-mail: Anthony.Leicht@jcu.edu.au
} 